\title{
Chapter 15 \\ Sense of Belonging: Predictors for Host Country Attachment Among Emigrants
}

\author{
Jean Philippe Décieux and Elke Murdock
}

\subsection{Introduction}

The twenty-first century has been described as the age of migration (Castles and Miller 2009). Germany has been affected by this trend, both as a target country for inward migration, and also as a country of emigration. Over the past decade, on average 180,000 persons with German citizenship have left the country (Ette and Erlinghagen 2021) and one in five Germans has lived at least three months abroad (Erlinghagen et al. 2021).

Yet the experiences of migrants from highly developed countries moving to different parts of the world are not well researched (Ette and Erlinghagen 2021). For this particular group of emigrants, the decision to leave is largely self-initiated as opposed to forced migration. The emigrants in our study voluntarily leave Germany, a developed country, mainly for work, lifestyle, or family reasons (Erlinghagen 2021). The German passport is the second most powerful passport in the world according to the Henley Passport Index allowing travel to 188 countries in the world without a visa or with visa-on-arrival (Visa-Germany 2020). Emigrants from Germany thus enjoy extensive freedom of travel and the vast majority of persons included in our sample have access to the host country's labour market (see Table 15.1). The emigrants included in our study thus face fewer barriers in terms of freedom of travel and labour market integration than forced migrants do. However, the self-initiated migrants will nevertheless need to adapt to life in their new, host society. Research shows that the experience of culture contact prompts reflection on

\footnotetext{
J. P. Décieux $(\bowtie)$

Institute of Sociology, University of Duisburg-Essen, Duisburg, Germany

e-mail: jean.decieux@uni-due.de

E. Murdock

Institute for Research on Generations and Family, University of Luxembourg,

Esch-sur-Alzette, Luxembourg

e-mail: elke.murdock@uni.lu
} 
Table 15.1 Descriptive statistics

\begin{tabular}{|c|c|c|c|}
\hline & $\begin{array}{l}\% \text { or mean } \\
\text { (SD) }\end{array}$ & & $\begin{array}{l}\% \text { or } \\
\text { mean } \\
(\mathrm{SD})\end{array}$ \\
\hline Dependent variables & & Socio-economic variables & \\
\hline $\begin{array}{l}\text { Feeling little or no attachment with the } \\
\text { host country }\end{array}$ & $50.0 \%$ & No degree, drop out, or other & $3.4 \%$ \\
\hline $\begin{array}{l}\text { Feeling attachment or strong } \\
\text { attachment with the host country }\end{array}$ & $50.0 \%$ & Secondary Education & $2.4 \%$ \\
\hline Socio-demographic variables & & Intermediate School Degree & $7.9 \%$ \\
\hline Male & $48.9 \%$ & Upper Secondary Degree & $86.1 \%$ \\
\hline Female & $50.7 \%$ & Employed & $61.1 \%$ \\
\hline Age (years) & $36.5(11.1)$ & Self-employed & $8.5 \%$ \\
\hline Non-Migrant & $71.3 \%$ & Civil servant & $3.3 \%$ \\
\hline Migrant (first Generation) & $11.4 \%$ & Unemployed & $2.1 \%$ \\
\hline Migrant (second Generation) & $14.2 \%$ & Retired & $3.5 \%$ \\
\hline Migration background undifferentiable & $1.5 \%$ & Education \& training & $10.3 \%$ \\
\hline Single household & $31.6 \%$ & Not employed & $7.2 \%$ \\
\hline Couple household & $36.9 \%$ & Other & $3.3 \%$ \\
\hline Single parent & $1.4 \%$ & Geographical Distance & \\
\hline Couple with children $<=16$ & $17.0 \%$ & \multirow{2}{*}{$\begin{array}{l}\text { German-speaking neighbour } \\
\text { country }\end{array}$} & \multirow[t]{2}{*}{$33.4 \%$} \\
\hline Couple with children $>16$ & $0.9 \%$ & & \\
\hline Couple with children $<=$ and $>16$ & $0.7 \%$ & \multirow{2}{*}{$\begin{array}{l}\text { Non-German-speaking } \\
\text { neighbour country }\end{array}$} & \multirow[t]{2}{*}{$14.2 \%$} \\
\hline Other combination & $8.3 \%$ & & \\
\hline Health and locus of control & & Other European country & $25.1 \%$ \\
\hline Internal locus of control & $2.7(1.0)$ & Non-European country & $23.8 \%$ \\
\hline External locus of control & $5.7(1.0)$ & Language competence & \\
\hline Health (very) good & $82.2 \%$ & Rather bad & $22.5 \%$ \\
\hline Health satisfying & $13.3 \%$ & Rather good & $41.3 \%$ \\
\hline Health (very) bad & $3.9 \%$ & Native speaker & $35.8 \%$ \\
\hline $\begin{array}{l}\text { Prior contacts within the host } \\
\text { country }\end{array}$ & & $\begin{array}{l}\text { Number of close friends } \\
\text { within the host country }\end{array}$ & \\
\hline No & 25.1 & Lowest quartile & $29.1 \%$ \\
\hline Yes & 74.9 & Middle quartiles & $27.2 \%$ \\
\hline Difficulty of the transition & & Highest quartile & $25.2 \%$ \\
\hline Rather difficult & $20.1 \%$ & $\begin{array}{l}\text { Previous migration } \\
\text { experience }\end{array}$ & \\
\hline Rather easy & $79.4 \%$ & No & $36.6 \%$ \\
\hline Rather easy & $79.4 \%$ & Yes & $63.2 \%$ \\
\hline \multirow{3}{*}{$\begin{array}{l}\text { Development of the situation in the } \\
\text { circle of friends after emigration }\end{array}$} & & Intention to stay & \\
\hline & & $\begin{array}{l}\text { A maximum of one more } \\
\text { year }\end{array}$ & $9.6 \%$ \\
\hline & & A few more years & $37.6 \%$ \\
\hline Rather easy & $79.4 \%$ & Forever & $24.2 \%$ \\
\hline Worse & $36.1 \%$ & Don't know & $28.4 \%$ \\
\hline
\end{tabular}

Percentages may not sum up to 100 due to missing information. Source: GERPSw1, $N=4545$ 
one's own cultural traditions, as behaviours one is accustomed to may no longer be appropriate. This may be followed by a phase in which a reconciliation of differences is attempted, and this phase may culminate in a feeling of belonging in the host country (Tadmor and Tetlock 2006). Within this chapter, we explore this development of attachment to the host country and aim to identify factors contributing to this sense of belonging.

This is an important question, as "research on international assignments highlights psychological or sociocultural adjustment as the vital construct underlying the rewards and costs of experiences to individuals, their families, and their firms" (Bhaskar-Shrinivas et al. 2005, p. 257, italics in original). Based on data from the first wave of the German Emigration and Remigration Panel Study (GERPS), this chapter explores these patterns of belonging of recent emigrants from Germany with a focus on belonging in the host country. As research on international adjustment is still fragmented, this research makes an important contribution to understanding the sociocultural processes with regard to the emotional attachment towards the host country.

\subsection{Theoretical Background}

As noted in a recent Council of Europe Report (Barrett 2016), increased migration, growing diversity, and globalisation have a profound effect on people's identities. The emigrants included in our study are an example for this increase in migration and we investigated how their migration experiences affect their sense of belonging. In the following sections, we first briefly describe the concepts of need to belong and national identity. We then explore the culture contact situation in more depth and describe factors influencing the acculturation process and contributing to a sense of belonging in the host country.

\subsubsection{The Need to Belong}

In their seminal article on the need to belong, Baumeister and Leary (1995) stated that "much of what people do is done in the service of belongingness" (p. 498). Human beings have a pervasive drive to form and maintain at least a minimum quantity of lasting, positive, and significant interpersonal relationships. Relationships and groups are fundamental for survival. The importance of group membership was stressed in Tajfel et al. (1986) Social Identity Theory (SIT). Social identity is understood as that part of an individual's self-concept, which derives from the knowledge of being a social group member together with the value and emotional significance attached to that membership. Belonging to a group helps people survive psychologically and physically (Fiske 2010). Ashmore et al. (2004) introduced the term collective identity to describe categorical group membership. I am German-may be 
a categorical answer to the question Who are you? Membership in this group can be ascribed (born into) or achieved (acquisition of citizenship). Objective criteria such as a passport indicate a formal link to a group, and this group membership can be accompanied by a strong affective component (negative or positive) and vary in centrality for the person. In a qualitative study among native Luxembourgers the authors showed that the theme of belongingness and emotional attachment to the homeland was particularly strong for the older generation (Bichler et al. 2020). Being German might or might not be important to an individual's sense of identity. The participants in our study formally belong to the category "German" and had decided to leave this country. We aimed to assess to what extent the emigrants developed a sense of belonging in the host country and what factors may predict this bond with the host country. They might not formally belong to this host country, but might develop an affective bond.

Nationality is of course a complex collective category. Unifying objective criteria such as language, religion, or geography cannot be used to predict where state boundaries are: psychological considerations are decisive (Billig 1995). As Arts and Halman (2005) explained, national identity refers to "perceived distinctiveness, a possibility to distinguish oneself or a group from others" (p. 73). Thus national identity explains the ways in which members of a national group reflexively understand themselves (Condor 2011). Nations are in fact "imagined communities" (Anderson 2006). The imagery and imaginaries of islander identity was in fact explored by Burholt et al. (2013) through in-depth interviews with older residents of Irish island communities. The narratives showed that islanders apply over-arching categories forming a hierarchy in assigning islander status. Geertz (1973) described a nation as a group based on primordial affiliations, reflecting an understanding based on ancestry. Yet most historians would agree that nations themselves are constructed (Péporté 2011). Most theories of nations converge on two dimensions -- a model based on ancestry (ethnic models) or the civic, socially-constructed model (Brubaker 2009; Weinreich and Saunderson 2005). The former bases citizenship on ancestry (Jus sanguinis), whereas the latter is based on certain political structures and social contracts, which are in principal open to all.

Germany is often cited as an example for ethnic national identity, as ancestry has played a large role in who can become a German citizen (Brubaker 1996). However, Germany also has a conflicted history with ethnic-based nationalism and less restrictive citizenship laws have been introduced in the immigration reform in 2000. Today, the macro-level discourse in Germany offers competing narratives (Ditlmann et al. 2011). National-level belonging is a multifaceted field with added complexity for the German context. It is therefore interesting to explore how German nationals integrate as emigrants to new host societies. 


\subsubsection{The Process of Acculturation}

Even though the migration experience of participants included in this survey can be classified as privileged mobility because it takes place by choice, as emigrants they are expected to have nevertheless faced immigration-based acculturation challenges (Chen et al. 2008). All participants will have spent a significant part of their lives in their country of origin, which in this case was Germany. They will have been socialised and enculturated into this society and now live in a different country with different institutions, values, cultures, and systems. Although research on migrants to Germany exists (e.g. Maehler and Schmidt-Denter 2012), to date the acculturation experience of German citizens moving to other countries has been neglected, as noted above.

Acculturation describes the process when individuals are exposed to prolonged culture contact (Celenk and van de Vijver 2014). The cultural practices or reference points individuals may have held prior to departure might only become apparent when exposed to a different cultural frame of reference (Straub 2003). The effect of second culture exposure as a central catalyst for self-reflection lies at the core of the acculturation complexity model (ACM) introduced by Tadmor and Tetlock (2006). These authors noted that the exposure to another culture leads initially to an increased attention scope. People may become sensitized to their own values. This host country culture exposure thus prompts reflection at first. Second, the negotiation of value conflicts between their own and the new culture of the host society may follow. The outcome of this negotiation process depends on what the authors have termed "accountability pressures". These refer to the need to justify one's own thoughts and actions to significant others. It is possible that an individual becomes attached to two cultures (e.g. bicultural).

The ACM model works best when the differences between two cultures are large enough to be challenging, but are not so large as to be overwhelming. As Tadmor and Tetlock (2006) noted, there appears to be an inverted U-shaped relationship between the size of the cultural differences experienced and the amount of cognitive effort expended in negotiating the difference. At the extreme difference end, the differences may be too large to be integrated. At the low difference end, the differences may be too subtle to be noted. These findings have implications for the relationship between the host country and emigrant's sense of belonging: If the cultural distance is large, it will be more difficult to develop a strong sense of belonging. If the countries are very similar, the emigrant will also be less likely to develop attachment to the host country. 


\subsubsection{Models of Adjustment}

The acculturation challenges of expatriates, specifically employees sent to work abroad for long periods of time, were the focus of the international adjustment model developed by Black et al. (1991). This model is most frequently cited within the body of research on emigrant adjustment and one contribution of this model is its multifaceted conceptualisation of the adjustment process. According to the authors, adjustment comprises cultural, interaction, and work adjustment. Cultural adjustment refers to comfort with the general living conditions of the host society. Interaction refers to the perceived quality of contacts with the host society. Finally, work adjustment refers to all aspects pertaining to the professional engagement. There is some overlap of these facets of adjustment with the seminal work on migration by Esser (1980). Esser distinguished between four dimensions of integration: (1) Structural factors ("Platzierung") overlaps with Black et al.'s work adjustment as it refers to access to the labour market, but goes further to include education, legal status, etc.; (2) cognitive factors ("Kulturation") refer to competences such as language ability and knowledge about local customs, encompassing Black et al.'s cultural adjustment.; (3) social factors ("Interaktion") refer mainly to relationships, signifying social contacts, networks, and relationships, which corresponds to Black et al.'s interaction adjustment category. However, Esser distinguished a further dimension, namely (4) emotional integration ("Identifikation") denoting an attachment or sense of belonging.

For the purpose of the present analysis, we were not interested in the specifics of work adjustment/labour market integration and structural integration. Rather, we were interested in the cultural and social factors of adjustment and their relationship with the fourth component, the emigrants' identification with or emotional attachment to their host country. In their meta-analytic review of empirical evidence regarding international adjustment, Bhaskar-Shrinivas et al. (2005) pointed out that especially anticipatory factors such as previous experience and language ability, individual-level factors (i.e. traits such as self-efficacy and relational skills), and non-work-related factors such as culture novelty are important for overall adjustment. Apart from these factors, which will be explained in more detail below, time plays an important role in the adjustment process. Bhaskar-Shrinivas et al. (2005) identified a side-ways " $\mathrm{S}$ " as the best fitting model for time adjustment. After the traditional "honeymoon" period in the first few months, a period of disorientation followed. After three years, the curve bottoms out, adjustment levels rise again and stay elevated. This pattern is important, as most of the participants in our study are fairly recent emigrants and may still find themselves in the honeymoon period in terms of adjustment. Nevertheless, we present analyses below to address this question of whether the participants' have developed feelings of belonging in the host country after the relatively short duration of time living in that country. 


\subsubsection{Anticipatory Factors}

Black et al. (1991) first identified anticipatory factors that refer to pre-departure experiences that impact adjustment. These factors include for example language ability or previous international experience. The meta-analytic review by BhaskarShrinivas et al. (2005) confirmed that the ability to speak the host country language facilitates host country adjustment. In line with that finding, Selmer and Lauring (2015) investigated the relationship between the difficulty of the language of a host country and emigrants' adjustment. As language affects almost all aspects of everyday life, the ability to use the host country language may ease the emigrant's adjustment. In host countries with languages that are challenging in terms of complexity and phonetics, few emigrants may be able to achieve mastery. However, greater skill using the host country's language might foster emigrants' adjustment and attachment. If a host country language is relatively easy to learn, proficiency can be gained relatively quickly, which will also ease adjustment, but the attachment may not go as deep. As Selmer and Lauring (2015) summarized, “... the benefits of language proficiency for ... adjustment may be contingent on the difficulty of the host country language" (p. 402). Moreover, the authors demonstrated that language difficulty indeed moderated socio-cultural adjustment. In case of mastery of a difficult host country language, emigrants had a stronger positive association and socio-cultural adjustment, compared to cases of mastery of a relatively easy host country language.

Apart from language competence, international experience may also ease adjustment. Following Rudmin (2009), who framed acculturation as a learning process, it can also be inferred that certain competences are required and can be learned in order to successfully operate in a new environment. Therefore, repeated movers should find it easier to adjust to new environments as it can be assumed that they have acquired the necessary competences required for adjustment. However, results from the meta-analytic review showed that previous migration experience only had a very small effect and the authors stated that previous experience had little practical use as predictive tool (Bhaskar-Shrinivas et al. 2005). Examining the time spent on overseas assignment is suggested as a more promising route. For the purposes of our analysis we take this suggestion into consideration by looking at the intended length of stay. We assume that with increasing intended permanence, level of identification with the host country will rise.

\subsubsection{Individual-Level Factors}

Black et al. (1991) suggest self-efficacy and relational skills as individual-level factors facilitating adjustment. Self-efficacy refers to belief in one's own abilities to execute plans of action and is closely related to internal control conviction. For the process of acculturation, agency plays an important role. In fact, Chirkov (2009) 
described acculturation at the individual level as "... a process that is executed by an agentic individual (it is not a process that happens to an individual) that takes place on entering a new cultural community" (Chirkov 2009, p. 94). We can infer that individuals who believe that events in their lives derive from their own actions, who have a strong internal locus of control, may adjust better to their new environments. Relational skills refer to the repertoire in forming interpersonal relationships. As noted above, being able to form relationships is central to survival. If the emigrant is able to form ties and relationships with members of the host culture, this will facilitate the adjustment process, as the emigrants will gain information also about the customs and acceptable behaviours of the host culture and will ultimately feel more at home.

\subsubsection{Cultural Distance}

The ease of adjustment may also be influenced by the cultural distance of the host country. Cultural distance refers to the perceived similarity between the home and host country. Cultural distance does not refer to the geographic distance, but rather the distance in terms of values (Inglehart and Welzel 2005). Context factors are also taken into consideration in Black et al. (1991)'s model and culture novelty was identified as an important factor in the adjustment process in the meta-analytic study by Bhaskar-Shrinivas et al. (2005). As the authors point out, smaller perceived differences between host and native cultures fosters adaptation. This sheds new light on the previously held assumption that cultural exposure should be exhilarating and uplifting (Harrison et al. 2004).

\subsubsection{Analytical Approach of this Chapter}

These theoretical deliberations and prior empirical findings highlight the idea that several factors predict host country adjustment. We presumed that these factors would also play a role in developing a sense of belonging to the host country and aimed to test several hypotheses. Starting with anticipatory factors referring to predeparture experiences, we made the following assumptions:

H1 Since acculturation is framed as a learning processes, we assumed that prior international experience facilitates the adjustment process and thereby positively contributes to host country belonging.

H2 Host country language competence facilitates the sense of belonging. 
H3 The intended length of stay, as a form of agency, plays an important role in the development of a sense of belonging. We assumed a significant positive relationship between the intention to stay "forever" and host country sense of belonging.

Regarding individual level factors, we derived the following hypotheses:

H4 Higher traits of internal locus of control help the adjustment process-as the emigrant feels agency.

H5 Being socially integrated facilitates adjustment. Therefore, we assumed that emigrants who develop friendship networks in their host country develop a stronger sense of belonging to that host country.

Finally, the target country or rather the cultural distance of the host country to the home country also plays an important role. We assumed a U-shaped relationship such that a sense of belonging is stronger in those countries that provide some cultural novelty but are not too distant in terms of values from the home country.

H6 Specifically, we predicted that emigrants to German-speaking neighbouring countries would express lower levels of sense of belonging, as the culture contact experience is too similar.

\subsection{Data and Methods}

The analysis is based on the first wave of GERPS. For this study a random sample is drawn from local population registers and covers 20- to 70-year-old German nationals who either emigrated from or re-migrated to Germany during the period between July 2017 and June 2018 (Ette et al. 2021). For the analysis of this chapter we only focus on emigrants from Germany and drew a sub-sample consisting of 4545 individuals.

\subsubsection{Measures}

The selection of measures was guided by the multidimensional adjustment model developed by Black et al. (1991), the dimensions suggested by Esser (1980), and insights from acculturation research.

The dependent variable in this chapter is emigrants' attachment to the new host country and refers to Esser (1980)'s fourth dimension of identification. Within GERPS, respondents had to answer the question "How strongly do you feel attached to the country you are currently living in: the country as a whole and its citizens?" on a four-point Likert scale from 1 "Strongly identify" to 4 "Don't identify at all". The answers are mainly found in the two middle categories "rather connected" and "rather not connected". For this reason, we dichotomized the scale and calculated 
logit models were chosen for ease of interpretation. Respondents who stated that they did rather weakly identify or not identify at all were coded as 0 and respondents who strongly or rather strongly identified with their host country were coded as 1 . However, we also calculated generalised ordered logit models based on the categorical variable as robustness check, which led to comparable results.

Consistent with the analytical strategy of this chapter, the explanatory variables can be divided into the three different dimensions. The first dimension refers to anticipatory factors as identified by Black et al. (1991) and include factors such as previous migration experience. Previous migration experience was captured by the question of whether respondents had always lived in Germany prior to the present migration, or had migrated once before, twice, or three or more times. Participants were also asked about their prior contact with people within the host country. Participants could indicate if they had known persons (e.g. family, friends, colleagues) in their host country before migration. Participants also rated the selfperceived difficulty of the transition to the emigration country on a scale from 1 "very difficult" to 6 "very easy". The scale was then transformed into a two-point scale of 1 "rather difficult" and 2 "rather easy". Language competence is another important anticipatory factor. Participants rated their host country language competence on a scale from 1 "native speaker" to 3 "rather bad".

The second dimension addresses individual factors and focuses on emigrants' personality traits and social integration. Regarding personality factors, we assessed internal and external locus of control convictions. Internal and external locus of control were measured using the ID-4 scale developed by Kovaleva et al. (2012). Social integration was measured by analysing the size and the subjectively perceived developments within emigrants' friendship networks. Friendship network size is based on emigrants' self-reported number of close friends within their host country. Based on the answers, respondents were assigned a quartile position. This was with the values 0 "Lowest quartile" for those reporting a relatively low number of close friends, 1 "Middle quartiles" for those reporting a number around the average, and 2 "Highest quartile" respondents reporting high numbers of close friends within the emigration country. A second self-report question addressed the subjectively perceived development of the size of the circle of friends after emigration.

The final dimension captures cultural distance between Germany and the host countries. Here we distinguish between German-speaking and non-Germanspeaking neighbour countries, other European countries, and non-European countries. Within two sub-models (model $2 \mathrm{a}$ and $2 \mathrm{~b}$ ), we further separate the analysis into only non-German-speaking neighbour countries in model $2 \mathrm{a}$ and Germanspeaking neighbour countries in model $2 \mathrm{~b}$ (see also the method section of this paper).

Moreover, all models are controlled for different respondents' characteristics (sociodemographic variables: age, age $^{2}$, gender, household status, employment status, education, migration background, subjective health status). Table 15.1 provides the descriptive statistics for all variables included in our analyses. 


\subsubsection{Method}

For all models in this chapter, binary logistic regression models (logit models) were calculated to estimate the influence of different explaining and controlling variables on the dependent variable, which is the attachment to the emigration country. Within these the average marginal effects (AME) were interpreted as these allow comparison between different models or even random samples (Auspurg and Hinz 2011; Mood 2010). The AME expresses the average influence of a model variable over all observations-given their characteristics-on the probability of the outcome $P(y=1$ l $x$ ) (Best and Wolf 2015). In all models, we controlled for different respondent characteristics (sociodemographic variables: age, age $^{2}$, gender, household composition, employment status, education, migration background, risk attitude, subjective health status).

In all models comparing geographical subgroups robust standard errors were estimated due to the risk of heteroscedasticity (Hoechle 2007). As a large subset of our sample emigrated to German-speaking neighbour countries, we calculated two separate models. In model 2a German-speaking neighbour countries were omitted. Model $2 \mathrm{~b}$ includes only on the sub-sample of respondents who moved to a Germanspeaking country. Moreover, we excluded language competence in model 2 and $2 \mathrm{~b}$ due to high risks of multicollinearity (Midi et al. 2010).

\subsection{Results}

The descriptive statistics in Table 15.1 show that about $50 \%$ of our respondents were identifying with their new, current host country. Thus, half of our participants expressed a sense of belonging in their host country. Below, we aim to identify the factors that contributed to this emotional attachment.

In a first step, we focused on a base model consisting of all our control variables that measured the sociodemographic background of our respondents as well as their health status and locus of control.

Table 15.2 shows that several individual factors are significantly related to expressing attachment to the new host country. Age, upper secondary school degree, not being employed, and medium or poor health seem to be negatively related to attachment to the emigration country. On the other hand, being female, second generation migration status in Germany, being self-employed, and being of rather good health appear to be positively related to attachment to the new host country. However, as indicated by the low pseudo $R^{2} 0.03$, most control variables appear to be only weakly related to emotional attachment.

In the next step, we therefore focused on more specific explanatory variables and their relationship to the emotional attachment to the emigration country. Table 15.3 
Table 15.2 Logit model reflecting the relationship between emotional attachment to the host country and the control variables

\begin{tabular}{|c|c|}
\hline & AME \\
\hline \multirow[t]{2}{*}{ Age } & $-0.017 * *$ \\
\hline & $(0.004)$ \\
\hline \multirow[t]{2}{*}{$\mathrm{Age}^{2}$} & $0.000 * * *$ \\
\hline & $(0.000)$ \\
\hline \multirow[t]{2}{*}{ Female (ref. male) } & $0.048 * *$ \\
\hline & $(0.002)$ \\
\hline \multicolumn{2}{|l|}{$\begin{array}{l}\text { Migration background (ref. no } \\
\text { migration background) }\end{array}$} \\
\hline \multirow[t]{2}{*}{ 1st Generation } & 0.033 \\
\hline & $(0.163)$ \\
\hline \multirow[t]{2}{*}{ 2nd Generation } & $0.049 *$ \\
\hline & $(0.022)$ \\
\hline \multirow{2}{*}{$\begin{array}{l}\text { Migration background, not } \\
\text { differentiable }\end{array}$} & 0.083 \\
\hline & $(0.166)$ \\
\hline \multicolumn{2}{|l|}{$\begin{array}{l}\text { Household composition (ref. } \\
\text { 1-person household) }\end{array}$} \\
\hline \multirow[t]{2}{*}{ Couple without Children } & -0.003 \\
\hline & $(0.860)$ \\
\hline \multirow[t]{2}{*}{ Single Parent } & 0.028 \\
\hline & $(0.669)$ \\
\hline \multirow[t]{2}{*}{ Couple with children $<=16$} & -0.015 \\
\hline & $(0.524)$ \\
\hline \multirow[t]{2}{*}{ Couple with children $>16$} & 0.090 \\
\hline & $(0.299)$ \\
\hline \multirow[t]{2}{*}{ Couple with children $<=$ and $>16$} & 0.071 \\
\hline & $(0.415)$ \\
\hline \multirow[t]{3}{*}{ Other combination } & $0.087 * *$ \\
\hline & $(0.002)$ \\
\hline & AME \\
\hline \multicolumn{2}{|c|}{$\begin{array}{l}\text { Education (ref. no degree, drop out, } \\
\text { or other) }\end{array}$} \\
\hline \multirow[t]{2}{*}{ Secondary Education } & 0.004 \\
\hline & $(0.953)$ \\
\hline \multirow[t]{2}{*}{ Intermediate School Degree } & 0.037 \\
\hline & $(0.440)$ \\
\hline \multirow[t]{2}{*}{ Upper Secondary Degree } & $-0.086^{*}$ \\
\hline & $(0.038)$ \\
\hline \multicolumn{2}{|l|}{ Employment status (ref. employed) } \\
\hline \multirow[t]{2}{*}{ Self-employed } & $0.117 * * *$ \\
\hline & $(0.000)$ \\
\hline
\end{tabular}

(continued) 
Table 15.2 (continued)

\begin{tabular}{l|l}
\hline & AME \\
\hline Civil servant & -0.072 \\
\hline Unemployed & $(0.082)$ \\
\hline & 0.017 \\
\hline Retired & $(0.748)$ \\
\hline & 0.020 \\
\hline Education \& training & $(0.728)$ \\
\hline & 0.013 \\
\hline Not employed & $(0.630)$ \\
\hline & $-0.073^{*}$ \\
\hline Other & $(0.017)$ \\
\hline Health status (ref. rather good) & $-0.105^{* *}$ \\
\hline Medium & $(0.009)$ \\
\hline & $-0.094^{* * *}$ \\
\hline Rather bad & $(0.000)$ \\
\hline Observations & $-0.178^{* * *}$ \\
\hline Pseudo $R^{2}$ & $(0.000)$ \\
\hline Stand & 4524 \\
\hline
\end{tabular}

Standard errors in parentheses; Source: GERPSw1 ${ }^{*} p<0.05,{ }^{* *} p<0.01,{ }^{* * *} p<0.001$

shows two different logit regression models focusing on factors that may be related to the emotional attachment to the host country.

When comparing the three models as presented in Table 15.3 it is notable that the patterns of relationships are very similar across all three models with one exception, namely the measure of geographical distance. When focusing on all host countries (model 2), we see a significant positive relationship with attached to other European countries and a slight positive relationship with attachment to non-European countries. This effect disappears when focusing only on non-German-speaking countries (model 2a). In model 2a, no significant relationship between geographical distance and identification can be found and the polarity of the coefficients associated with this relationship are reversed.

Respondents' language competence appears to play an important role in feeling attached to the host country. In model $2 \mathrm{a}$, we observed a highly significant, positive relationship between emigrants' indicating that they speak the language at least rather well and their reported host country attachment. The relationship between country attachment and language competence is particularly strong for native speakers in non-European host countries. The findings suggest that language competence and emotional attachment are positively related such that the greater language competence in the host country language is, the stronger identification with the host country, and vice versa. Moreover, we found a relationship between locus of control and host country attachment. Although we only found a negative relationship between external locus of control and emotional attachment to the host country in 
Table 15.3 Logit models reflecting the relationship of different influential variables and the attachment to the host country (Showing the AMEs)

\begin{tabular}{|c|c|c|c|}
\hline & $\begin{array}{l}\text { (2) All host } \\
\text { countries }\end{array}$ & $\begin{array}{l}\text { (2a) Non-German- } \\
\text { speaking countries }\end{array}$ & $\begin{array}{l}\text { (2b) German-speaking } \\
\text { neighbour countries }\end{array}$ \\
\hline \multicolumn{4}{|c|}{ Cultural distance (ref. German-speaking neighbour country) } \\
\hline \multirow[t]{2}{*}{ Neighbour country } & $0.077 * * *$ & \multirow[t]{2}{*}{ Ref. } & \\
\hline & $(0.000)$ & & \\
\hline \multirow{2}{*}{$\begin{array}{l}\text { Other European } \\
\text { country }\end{array}$} & $0.097 * * *$ & -0.003 & \\
\hline & $(0.000)$ & $(-0.120)$ & \\
\hline \multirow{2}{*}{$\begin{array}{l}\text { Non-European } \\
\text { country }\end{array}$} & $0.087 * * *$ & -0.024 & \\
\hline & $(0.000)$ & $(-1.040)$ & \\
\hline \multicolumn{4}{|c|}{$\begin{array}{l}\text { Language competence (ref. (rather) } \\
\text { bad) }\end{array}$} \\
\hline \multirow[t]{2}{*}{ (Rather) good } & & $0.124 * * *$ & \\
\hline & & $(6.160)$ & \\
\hline \multirow[t]{2}{*}{ Native speaker } & & $0.198 * * *$ & \\
\hline & & $(6.140)$ & \\
\hline \multicolumn{4}{|c|}{ Prior contacts within the host country (ref. no) } \\
\hline \multirow[t]{2}{*}{ Yes } & $0.052 * *$ & $0.058 * *$ & -0.007 \\
\hline & $(0.001)$ & $(2.950)$ & $(-0.230)$ \\
\hline
\end{tabular}

Number of close friends within the host country (ref. middle quartiles)

\begin{tabular}{|c|c|c|c|}
\hline \multirow[t]{2}{*}{ Lower quartile } & $-0.092 * * *$ & $-0.090 * * *$ & $-0.062 *$ \\
\hline & $(0.000)$ & $(-3.840)$ & $(-1.990)$ \\
\hline \multirow[t]{2}{*}{ Higher quartiles } & $0.080 * * *$ & $0.072 * *$ & $0.0769 *$ \\
\hline & $(0.000)$ & $(3.000)$ & $(2.31)$ \\
\hline \multicolumn{4}{|c|}{$\begin{array}{l}\text { Previous migration experience (ref. } \\
\text { no) }\end{array}$} \\
\hline \multirow[t]{2}{*}{ Yes } & 0.000 & 0.010 & -0.008 \\
\hline & $(0.978)$ & $(0.520)$ & $(-0.310)$ \\
\hline \multicolumn{4}{|c|}{$\begin{array}{l}\text { Intention to stay (ref. a maximum of } \\
\text { one year) }\end{array}$} \\
\hline \multirow[t]{2}{*}{ A few more years } & $0.114 * * *$ & $0.119 * * *$ & $0.144^{*}$ \\
\hline & $(0.000)$ & $(4.170)$ & $(2.010)$ \\
\hline \multirow[t]{2}{*}{ Forever } & $0.354 * * *$ & $0.322 * * *$ & $0.397 * * *$ \\
\hline & $(0.000)$ & $(9.730)$ & $(5.580)$ \\
\hline \multirow[t]{2}{*}{ Don't know } & $0.174 * * *$ & $0.152 * * *$ & $0.220 * *$ \\
\hline & $(0.000)$ & $(5.010)$ & $(3.080)$ \\
\hline
\end{tabular}

Development of the situation in the circle of friends after emigration (ref. equal)

\begin{tabular}{l|l|l|l}
\hline Better & 0.036 & 0.0218 & 0.054 \\
\hline & $(0.063)$ & $(0.930)$ & $(1.710)$ \\
\hline Worse & $-0.122 * * *$ & $-0.128 * * *$ & $-0.096 * * *$ \\
\hline & $(0.000)$ & $(-6.28)$ & $(-3.46)$ \\
\hline
\end{tabular}


Table 15.3 (continued)

\begin{tabular}{|c|c|c|c|}
\hline & $\begin{array}{l}\text { (2) All host } \\
\text { countries }\end{array}$ & $\begin{array}{l}\text { (2a) Non-German- } \\
\text { speaking countries }\end{array}$ & $\begin{array}{l}\text { (2b) German-speaking } \\
\text { neighbour countries }\end{array}$ \\
\hline \multicolumn{4}{|c|}{ Difficulty of the transition (ref. rather difficult) } \\
\hline \multirow[t]{2}{*}{ Rather easy } & $0.094 * * *$ & $0.0733 * * *$ & $0.111 * * *$ \\
\hline & $(0.000)$ & $(3.430)$ & $(3.380)$ \\
\hline \multirow{2}{*}{$\begin{array}{l}\text { External. locus of } \\
\text { control }\end{array}$} & -0.013 & $-0.021 * *$ & 0.002 \\
\hline & $(0.054)$ & $(0.010)$ & $(0.866)$ \\
\hline \multirow{2}{*}{$\begin{array}{l}\text { Internal locus of } \\
\text { control }\end{array}$} & $0.019 *$ & $0.020 *$ & 0.021 \\
\hline & $(0.011)$ & $(0.030)$ & $(0.123)$ \\
\hline Observations & 4524 & 3010 & 1513 \\
\hline Pseudo $R^{2}$ & 0.135 & 0.160 & 0.134 \\
\hline
\end{tabular}

Standard errors in parentheses; ${ }^{*} p<0.05,{ }^{* *} p<0.01,{ }^{* * *} p<0.001$, model controlled as well for age, $\mathrm{age}^{2}$, gender, household composition, employment status, education, migration status, and health status. Source: GERPSw1

model 2, which included all host countries, we detected a significant positive relationship between emotional attachment to the host country and both traits of locus of control, internal and external locus, in model 2a that was restricted to only nonGerman speaking countries. Additionally, in model $2 b$ that only included Germanspeaking neighbour countries, no significant relationship between locus of control and emotional attachment to the host country was found. Furthermore, being socially integrated seems to be an important explanatory construct that is positively related to the emotional attachment of emigrants to their host countries. Respondents who had a relatively high number of friends within the host country and respondents who expressed ease at the host country transition also reported higher levels of attachment to their emigration country. Furthermore, respondents who specified that the development of their circle of friends has become worse compared to the situation before their emigration and respondents with a quantitatively lower reported number of close friends within the host country also expressed a lower level of attachment to their host country in all three models, as shown in Table 15.3.

Contact with individuals within the host country prior to emigration seemed to be an important variable for emigrants in non-German-speaking countries, as we found a significant relationship between prior contacts and emigrants' emotional attachment to the host country only in models (2) and (2a). For model (2b), which included only emigrants within German-speaking countries, we observed a negative relationship that was non-significant. Finally, although previous migration experience played only a negligible role in relation to forming attachment to the emigration country, the intention to stay within the host country was significantly related to it. The intention to stay for at least for a few more years, but also indecisive responses (e.g. "don't know yet") were positively linked with attachment. However, the strongest association with host country attachment was found for those who stated that they intended to stay forever. These findings suggest that permanence, or the intention to stay forever, is an important factor for the development of host country attachment. 


\subsection{Conclusion}

As (Connolly 2020) recently observed "When we think about movements of population, we tend to mean from poorer countries to richer ones in search of a better life. Things are more complex if it's between countries with roughly similar levels of prosperity." One complex area that is not yet well researched is the question of belonging for emigrants who leave a developed country voluntarily. Do these migrants develop a feeling of belonging to their chosen host country? What are the factors influencing the development of host country attachment? These are questions we set out to answer in this chapter.

In contrast to most previously studied emigrant groups, the vast majority of our emigrants were highly skilled and educated and as German citizens they have permission to travel (Visa-Germany 2020). The majority of the emigrants in our study were asp employed in the host country. When these factors are taken together, settlement into the new environment may be relatively easy. Therefore, it is especially interesting to explore if and how this specific group of self-initiated emigrants emotionally identifies with the new host society.

The first question is answered easily: On average, our sample participants had spent around 12 months in their destination country at the time of the interview and $50 \%$ expressed a feeling of attachment to their new host country. Thus, half of our participants expressed a sense of attachment to their host country. Most of our emigrants were at an early stage of their migration process and-as indicated within the theoretical framework-research points out that acculturation and identification are considered to be a dynamic result of cultural contact and interaction of individuals with their social contexts (Celenk and van de Vijver 2014). There may be two plausible explanations for these results. First, the emigrants might still find themselves in the honeymoon period of adjustment, which is often observed within the first few months after migration (Bhaskar-Shrinivas et al. 2005). Another plausible explanation might be that these emigrants already felt connected to their host destination before their current migration. Possibly, this pre-existing connection with or affinity for the emigration country may have been an important motive for the voluntary emigration to that country. The first explanation we can only test in future surveys and through exploration of the shape of the curve of adjustment over time. For the second explanation, we require more data on the "pre-migration history" referring to processes directly before and leading up to the migration decision. For future waves, this will be possible to elucidate based on data regarding respondents' becoming internationally mobile again and by this multiple migrants, e.g. remigrants who migrate abroad again and are considered to be "panel-emigrant", emigrants who migrate back to Germany and are tracked as "panel-remigrant", or emigrants who move on to another country abroad and get the status of a panelonmigrant. For those respondents, the level of information concerning their life situation, motivation for migration, and the "pre-migration history" is much more detailed. 
Having established that our participants indeed develop an attachment to their host country, we now turn to the factors having a potential bearing on this process, starting with anticipatory factors. In line with other findings in the adjustment literature, our data show that prior migration experience plays only a minor role ( $\mathrm{H} \mathrm{1}$ ) (Bhaskar-Shrinivas et al. 2005). Language is of course a key vehicle that allows the migrant to access and experience different facets of the host society and we did find a relationship between language competence and sense of belonging ( $\mathrm{H} 2)$. However, the findings in relation to language are more complex. Emigrants' self-reported language competence does foster attachment to the host country, however the relationship is strongest for native language competence in a non-German context. This finding is in line with Selmer and Lauring (2015) finding that language difficulty is related to adjustment. Mastery of a difficult host country language was positively associated with host country adjustment. As proposed in H3, intended length of stay in the host country is an important predictor for host country attachment. The intention to stay "forever" was strongly and positively related to a feeling of attachment to the host country. The importance of agency in the acculturation process is stressed by Chirkov (2009) and we can infer that persons who self-initiate a move with an intention to stay permanently may also invest more emotionally in this new host country as it was their decision to leave their previous country and settle there. Thus, the development of attachment to the new host country after a relatively short time spent in the new country may be a unique finding related to our sample of selfinitiated migrants.

In terms of individual difference factors and the relationship assumed in $\mathrm{H} 4$, high levels of internal locus of control and low levels of external locus of control seemed to be related to stronger emotional attachment and again especially important in non-German-speaking countries. Thus, as proposed by Chirkov (2009), selfinitiative and active agency seems to be required within the process of emotional attachment especially in more culturally distant countries. Moreover, in line with Black et al. (1991) and H 5, we also found that relational factors played an important role. Our data clearly show that socially integrated emigrants reported higher emotional attachment to the host country. This relationship is stronger for nonGerman-speaking host countries. This is an interesting finding that may be related to the dynamics regarding cultural distance captured in $\mathrm{H} 6$.

Acknowledging in $\mathrm{H} 6$ that the cultural distance of a host country may play a role in the attachment process (Inglehart and Welzel 2005), we explored this cultural distance by distinguishing German-speaking neighbour countries, non-Germanspeaking neighbour countries, other European countries, and non-European countries. We did find that cultural distance matters: Emigrants living in German-speaking countries reported the lowest level of attachment to their host countries. However, if a country is different (i.e. not a German-speaking country) but not too culturally different, participants are more likely to develop attachment to the host country. In that sense, we were able to replicate the U-shaped relationship between the size of the cultural differences experienced and the amount of cognitive effort expended in negotiating the difference, as proposed by (Tadmor and Tetlock 2006). If the differences between countries are too small to be noted (i.e. German speaking 
neighbours) lower levels of emotional attachment will be developed. In countries that are very different it might be also more challenging to establish a sense of home. However, in the current model the country classification is not very refined. In the future a more fine-grained indicator based for example on the dimensions of (Hofstede 1983) might help to elaborate this finding.

In this chapter we set out to examine the development of host country attachment of emigrants from Germany, motivated by the finding that half of our respondents expressed an attachment to their host society. We identified important factors related to the development of host country attachment that mirror findings in the adjustment literature. Not surprisingly, the permanence of the intended stay was the strongest predictor. Social integration also plays an important role. Host country language competence is of course important for the adjustment and identification processes, but our data also replicate previous research findings, highlighting the role of language complexity. Attachment was stronger where German was not the local language. This dovetails into the finding of the U-shaped relationship regarding cultural distance. Some cultural novelty facilitates adjustment. As noted above, the classification of countries regarding cultural distance should be elaborated in future research. In the present study we only examined host country attachment after a relatively short time, on average 12 months, in the host country. Future GERPS study waves will allow us to monitor the attachment curves over time. Another interesting question is the relationship between home and host country attachment. As set out in the fourfold theory of acculturation by (Berry 1974, 1997), immigrants have the choice between the adoption of the host culture or maintenance of the heritage culture. Integration refers to the simultaneous attempt to retain attachment to the heritage culture, while adopting elements of the host culture. Assimilation refers to the adoption of the host culture and rejection of the heritage culture. The opposite is the case for the separation. When both cultures are rejected we speak about marginalisation. Building on this framework, we intend in a next step to focus on different attachment groups, i.e. those who indicate they feel attached to home and host country, those who express attachment to neither, or those who only identify with Germany. Using a multi-sited approach (FitzGerald 2012; Wimmer and Glick Schiller 2002), we aim to identify the factors contributing to mono-cultural attachment towards Germany or the host country, attachment to neither, or those who feel attached to both countries. A further question is whether the latter can be characterized as bi-cultural (Murdock 2016, 2017). Thus, the data presented in this chapter are only a first step in a much wider research frame. In terms of general methodological limitation of the results, we would like to point out that the data source in this chapter is only a cross-sectional sample with unobserved heterogeneity. This means that the results might, at least partly, be influenced by factors that are not controlled for within these models. In the future, with more waves of GERPS, longitudinal fixed-effect panel regressions can help to follow up these results and to separate actual effects from influence of potential unobserved third variables (Hamaker and Muthén 2019; Hsiao 2014).

Despite these limitations, this chapter allows us to empirically reflect on the development of host country attachment of an under-researched group of 
self-initiated, highly qualified emigrants. We identified important factors related to host country attachment that mirror findings in the adjustment literature. One important factor for the development of attachment is the emigrants' intention to stay-and this is probably a feature of the particular target group included in our sample-the self-initiated migrants. The data also show that there is a complex relationship between the cultural characteristics of the target country and the factors related to an emotional settlement in these differing cultural contexts, and these patterns of findings point to future avenues of research.

\section{References}

Anderson, B. (2006). Imagined communities: Reflections on the origin and spread of nationalism. London: Verso books.

Arts, W., \& Halman, L. (2005). National identity in Europe today: What the people feel and think. International Journal of Sociology, 35(4), 69-93.

Ashmore, R. D., Deaux, K., \& McLaughlin-Volpe, T. (2004). An organizing framework for collective identity: articulation and significance of multidimensionality. Psychological Bulletin, $130(1), 80$.

Auspurg, K., \& Hinz, T. (2011). Gruppenvergleiche bei Regressionen mit binären abhängigen Variablen: Probleme und Fehleinschätzungen am Beispiel von Bildungschancen im Kohortenverlauf. Zeitschrift für Soziologie, 40(1), 62-73.

Barrett, M. D. (2016). Competences for democratic culture: Living together as equals in culturally diverse democratic societies. Strasbourg, France: Council of Europe Publishing. Retrieved from http://www.coe.int/en/web/education/competences-for-democratic-culture. Accessed 1 October 2020.

Baumeister, R., \& Leary, M. (1995). The need to belong: Desire for interpersonal attachments as a fundamental human motivation. Psychological Bulletin, 117(3), 497-529.

Berry, J. W. (1974). Psychological aspects of cultural pluralism: unity and identity reconsidered. Topics in Culture Learning, 2, 17-22.

Berry, J. W. (1997). Immigration, acculturation, and adaptation. Applied Psychology, 46(1), 5-34.

Best, H., \& Wolf, C. (2015). Logistic regression. In H. Best \& C. Wolf (Eds.), The SAGE handbook of regression analysis and causal inference. London: SAGE Publications.

Bhaskar-Shrinivas, P., Harrison, D. A., Shaffer, M. A., \& Luk, D. M. (2005). Input-based and timebased models of international adjustment: Meta-analytic evidence and theoretical extensions. Academy of Management Journal, 48(2), 257-281.

Bichler, S., Albert, I., Barros, S., \& Murdock, E. (2020). Exploring cultural identity in a multicultural context-the special case of Luxembourg. Human Arenas, 3(3), 310-330.

Billig, M. (1995). Banal nationalism. London: SAGE.

Black, J. S., Mendenhall, M., \& Oddou, G. (1991). Toward a comprehensive model of international adjustment: An integration of multiple theoretical perspectives. Academy of Management Review, 16(2), 291-317.

Brubaker, R. (1996). Citizenship and nationhood in France and Germany. Harvard: Harvard University Press.

Brubaker, R. (2009). Ethnicity, race, and nationalism. Annual Review of Sociology, 35, 21-42.

Burholt, V., Scharf, T., \& Walsh, K. (2013). Imagery and imaginary of islander identity: Older people and migration in Irish small-island communities. Journal of Rural Studies, 31, 1-12.

Castles, S., \& Miller, M. J. (2009). The age of migration: International population movements in the modern world. Houndmills: Palgrave Macmillan. 
Celenk, O., and van de Vijver, F. J. R. (2014). Assessment of psychological acculturation and multiculturalism: An overview of measures in the public domain. The Oxford Handbook of Multicultural Identity 205-226.

Chen, S. X., Benet-Martínez, V., \& Bond, M. H. (2008). Bicultural Identity, bilingualism, and psychological adjustment in multicultural societies: immigration-based and globalization-based acculturation. Journal of Personality, 76(4), 803-838.

Chirkov, V. (2009). Critical psychology of acculturation: What do we study and how do we study it, when we investigate acculturation? International Journal of Intercultural Relations, 33(2), 94-105.

Condor, S. (2011). Towards a social psychology of citizenship? Introduction to the special issue. Journal of Community \& Applied Social Psychology, 21(3), 193-201.

Connolly, K. (2020). Wir sind Deutschbriten. https://www.bbc.co.uk/news/extra/DXCo3FIuNz/ we_are_british_germans. Accessed 1 October 2020.

Ditlmann, R. K., Purdie-Vaughns, V., \& Eibach, R. P. (2011). Heritage- and ideology-based national identities and their implications for immigrant citizen relations in the United States and in Germany. International Journal of Intercultural Relations, 35(4), 395-305.

Erlinghagen, M. (2021). Migration motives, timing, and outcomes of internationally mobile couples. In M. Erlinghagen, A. Ette, N. F. Schneider, \& N. Witte (Eds.), The global lives of German migrants. Consequences of international migration across the life course. Cham: Springer.

Erlinghagen, M., Ette, A., Schneider, N. F., \& Witte, N. (2021). Between origin and destination: German migrants and the individual consequences of their global lives. In M. Erlinghagen, A. Ette, N. F. Schneider, \& N. Witte (Eds.), The global lives of German migrants. Consequences of international migration across the life course. Cham: Springer.

Esser, H. (1980). Aspekte der Wanderungssoziologie. Assimilation und Integration von Wanderern, ethnischen Gruppen und Minderheiten. Eine handlungstheoretische Analyse. Darmstadt, Neuwied: Luchterhand.

Ette, A., Décieux, J. P., Erlinghagen, M., Auditor, J. G., Sander, N., Schneider, N. F., \& Witte, N. (2021). Surveying across borders: The experiences of the German emigration and remigration panel study. In M. Erlinghagen, A. Ette, N. F. Schneider, \& N. Witte (Eds.), The global lives of German migrants. Consequences of international migration across the life course. Cham: Springer.

Ette, A., \& Erlinghagen, M. (2021). Structures of German emigration and remigration: Historical developments and demographic patterns. In M. Erlinghagen, A. Ette, N. F. Schneider, \& $\mathrm{N}$. Witte (Eds.), The global lives of German migrants. Consequences of international migration across the life course. Cham: Springer.

Fiske, S. T. (2010). Social beings: Core motives in psychology. Hoboken, NJ: Wiley.

FitzGerald, D. (2012). A comparativist manifesto for international migration studies. Ethnic and Racial Studies, 35(10), 1725-1740.

Geertz, C. (1973). The interpretation of cultures. New York: Basic Books.

Hamaker, E. L., \& Muthén, B. (2019). The fixed versus random effects debate and how it relates to centering in multilevel modeling. Psychological Methods, 25, 365.

Harrison, D. A., Shaffer, M. A., \& Bhaskar-Shrinivas, P. (2004). Going places: Roads more and less traveled in research on expatriate experiences. Research in Personnel and Human Resources Management, 23, 199-247.

Hoechle, D. (2007). Robust standard errors for panel regressions with cross-sectional dependence. The Stata Journal, 7(3), 281-312.

Hofstede, G. (1983). National cultures in four dimensions: A research-based theory of cultural differences among nations. International Studies of Management \& Organization, 13(1-2), 46-74.

Hsiao, C. (2014). Analysis of panel data. Cambridge University Press.

Inglehart, R., \& Welzel, C. (2005). Modernization, cultural change, and democracy: The human development sequence. Cambridge University Press.

Kovaleva, A., Beierlein, C., Kemper, C. J., and Rammstedt, B. (2012). Eine Kurzskala zur Messung von Kontrollüberzeugung: Die Skala Internale-Externale-Kontrollüberzeugung-4 (IE-4). 
Maehler, D., \& Schmidt-Denter, U. (2012). Migrationsforschung in Deutschland: Leitfaden und Messinstrumente zur Erfassung psychologischer Konstrukte. Wiesbaden: VS Verlag.

Midi, H., Sarkar, S. K., \& Rana, S. (2010). Collinearity diagnostics of binary logistic regression model. Journal of Interdisciplinary Mathematics, 13(3), 253-267.

Mood, C. (2010). Logistic regression: Why we cannot do what we think we can do, and what we can do about it. European Sociological Review, 26(1), 67-82.

Murdock, E. (2016). Multiculturalism, Identity and Difference. London: Palgrave Macmillan.

Murdock, E. (2017). Identity and Its Construal: Learning from Luxembourg. Integrative Psychological and Behavioral Science, 51(2), 261-278.

Péporté, P. (2011). Constructing the middle ages: Historiography, collective memory and nationbuilding in Luxembourg. Leiden: Brill.

Rudmin, F. (2009). Constructs, measurements and models of acculturation and acculturative stress. International Journal of Intercultural Relations, 33(2), 106-123.

Selmer, J., \& Lauring, J. (2015). Host country language ability and expatriate adjustment: The moderating effect of language difficulty. The International Journal of Human Resource Management, 26(3), 401-420.

Straub, J.. (2003). Psychologie und die Kulturen in einer globalisierten Welt. A. Thomas (Hg.): Kulturvergleichende Psychologie, Göttingen 543-566.

Tadmor, C. T., \& Tetlock, P. E. (2006). Biculturalism: A model of the effects of second-culture exposure on acculturation and integrative complexity. Journal of Cross-Cultural Psychology, $37(2), 173-190$.

Tajfel, H., Turner, J. C., Austin, W. G., \& Worchel, S. (1986). An integrative theory of intergroup conflict. In S. Worchel \& W. G. Austin (Eds.), The social psychology of intergroup relations (pp. 33-47). Monterey: Brooks/Cole.

Visa-Germany. (2020). German passport holders can visit 188 countries without a prior visa. https://www.germany-visa.org/news/german-passport-holders-can-visit-188-countrieswithout-a-prior-visa/, accessed 1 October 2020.

Weinreich, P., \& Saunderson, W. (2005). Analysing identity: Cross-cultural, societal and clinical contexts. New York: Routledge.

Wimmer, A., \& Glick Schiller, N. (2002). Methodological nationalism and beyond: nation-state building, migration and the social sciences. Global Networks, 2(4), 301-334.

Open Access This chapter is licensed under the terms of the Creative Commons Attribution 4.0 International License (http://creativecommons.org/licenses/by/4.0/), which permits use, sharing, adaptation, distribution and reproduction in any medium or format, as long as you give appropriate credit to the original author(s) and the source, provide a link to the Creative Commons license and indicate if changes were made.

The images or other third party material in this chapter are included in the chapter's Creative Commons license, unless indicated otherwise in a credit line to the material. If material is not included in the chapter's Creative Commons license and your intended use is not permitted by statutory regulation or exceeds the permitted use, you will need to obtain permission directly from the copyright holder.

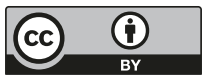

